${ }^{1}$ Ecologie Microbienne UMR-CNRS 5557 and INRA, Bât. G. Mendel, Université Claude Bernard-Lyon 1, 43 bd du 11 novembre 1918, 69622 Villeurbanne cedex, France

2 Biométrie, Génétique et Biologie des Populations UMR CNRS 5558, Université Claude Bernard-Lyon 1, Villeurbanne, France

\section{A mathematical method for determining genome divergence and species delineation using AFLP}

\author{
Christophe Mougel, ${ }^{1}$ Jean Thioulouse, ${ }^{2}$ Guy Perrière ${ }^{2}$ and Xavier Nesme ${ }^{1}$
}

Author for correspondence: Xavier Nesme. Tel: +33 4 72448289. Fax: + 33472431223.

e-mail: nesme@univ-lyon1.fr

The delineation of bacterial species is presently achieved using direct DNA-DNA relatedness studies of whole genomes. It would be helpful to obtain the same genomically based delineation by indirect methods, provided that descriptions of individual genome composition of bacterial genomes are obtained and included in species descriptions. The amplified fragment length polymorphism (AFLP) technique could provide the necessary data if the nucleotides involved in restriction and amplification are fundamental to the description of genomic divergences. Firstly, in order to verify that AFLP analysis permits a realistic exploration of bacterial genome composition, the strong correspondence between predicted and experimental AFLP data was demonstrated using Agrobacterium strain C58 as a model system. Secondly, a method is proposed for determining current genome mispairing and evolutionary genome divergences between pairs of bacteria, based on arbitrary sampling of genomes by using AFLP. The measure of current genome mispairing was validated by comparison with DNA-DNA relatedness data, which itself correlates with base mispairing. The evolutionary genome divergence is the estimated rate of nucleotide substitution that has occurred since the strains diverged from a common ancestor. Current genome mispairing and evolutionary genome divergence were used to compare members of Agrobacterium, used as a model of closely related genomic species. A strong and highly significant correlation was found between calculated genome mispairing and DNA-DNA relatedness values within genomic species. The canonical $70 \%$ DNA-DNA hybridization value used to delineate genomic species was found to correspond to a range of current genome mispairing of 13-13.6\%. These limits correspond to 0.097 and 0.104 nucleotide substitutions per site, respectively. In addition, experimental data showed that the large $\mathrm{Ti}$ and cryptic plasmids of Agrobacterium had little effect on the estimation of genome divergence. Evolutionary genome divergence was used for phylogenetic inferences. Data showed that members of the same genomic species clustered consistently, as supported by bootstrap resampling. On the basis of these results, it is proposed that the genomic delineation of bacterial species could be based, in future, on phylogenetic groups supported by bootstraps and genome descriptions of individual strains, obtained by AFLP analysis, recorded in accessible databases; this approach might eventually replace DNA-DNA hybridization studies.

Keywords: AFLP, genome divergence, evolutionary distance, phylogeny, Agrobacterium spp. 


\section{INTRODUCTION}

The consensus definition for bacterial species is currently based on DNA-DNA relatedness studies (Wayne et al., 1987). The genomic basis of bacterial species definition will still remain the 'gold standard' in bacterial taxonomy because it represents the underlying properties of bacteria. The zoological definition of a species is 'groups of potentially interbreeding populations that are reproductively isolated from other groups'. This definition stresses the requirement for reproductive isolation, which is also relevant to bacterial systematics. Sexuality exists in the Prokarya through conjugation, transformation and transduction. Even if the wide taxonomic range of bacterial recipients of some plasmids precludes the idea of complete reproductive isolation, the relatively small size of these autonomous genetic elements limits their impact on species delineation. In contrast, the entire genome is involved in integrative transformation. Integrative transformation is, however, limited to close relatives, because DNA recombination in the Prokarya is strictly controlled by both the SOS and mismatch repair systems (Matic et al., 1995). Thus, the lack of homologous recombination plays the same role in prokaryotes as sexual incompatibility does in animals in maintaining the genome integrity of a species. As a result, speciation in bacteria is determined by a phenomenon that hinders recombination between distantly related bacteria (Matic et al., 1995). Overall genome mispairing, currently measured by using DNA-DNA relatedness, is a fundamental concept in bacterial systematics.

DNA-DNA relatedness studies only establish direct genome comparisons, and the techniques involved are time-consuming and are difficult to apply to numerous strains (as is required for population genetics). Therefore, in order to find a method for comparing a large number of bacteria, genetic markers have been defined; this has aided the construction of appropriate databases suitable for indirect comparisons of bacteria (Perrière et al., 2000). rrs (16S rRNA) gene sequences have received considerable attention for that reason (Maidak et al., 2001). However, the resulting phylogeny is not sensitive enough to guarantee correct delineation of genomic species and, a fortiori, to study infraspecific diversity (Stackebrandt \& Goebel, 1994; Fox et al., 1992). Furthermore, as the method is used to consider a single locus, it is very sensitive to interspecific exchanges that introduce discrepancies between genomic and rrs-based phylogenies (Cohan, 1994; Yap et al., 1999; Wang \& Zhang, 2000). Alternative methods using multiple loci, such as multilocus sequencing (Spratt, 1999), or techniques using random or arbitrary amplification of genome fragments, such as randomly amplified polymorphic DNA analysis, the rep-PCR technique or amplified fragment length polymorphism (AFLP) analysis, have been proposed as methods complementary to DNADNA hybridization (Caetano-Anollés et al., 1991; Versalovic et al., 1991; Zabeau \& Vos, 1993). Among those later methods, AFLP has received considerable support for taxonomic studies (Janssen et al., 1996; Clerc et al., 1998; Hauben et al., 1999; Rademaker et al., 2000) because it yields a clear delineation of bacteria belonging to the same genomic species (Clerc et al., 1998). Validation of AFLP analysis as an alternative to DNA-DNA relatedness studies requires AFLP to be a descriptor of the genome structure and the demonstration of its relationship to DNA-DNA hybridization values.

The genus Agrobacterium is a good model for investigating the relatedness between DNA-DNA hybridization values and genome similarities obtained from AFLP. Conventional morpho-biochemical criteria recognize three biovars, as well as agrobacteria too distantly related to be included in these biovars (Keane et al., 1970; Kersters et al., 1973; Panagopoulos et al., 1978; Bouzar et al., 1995a; Bouzar \& Jones, 2001). DNA-DNA hybridization studies supported by $16 \mathrm{~S}$ rDNA analysis showed that the biovars correspond well to genomic species, corresponding (in two instances) to well-characterized nomenspecies : biovar 3, corresponding to Agrobacterium vitis, and biovar 2, corresponding to Agrobacterium rhizogenes (Ophel \& Kerr, 1990; Sawada et al., 1993; Yanagi \& Yamasato, 1993). The case of biovar 1 is, however, much more complex. Proposals to define a single species for members of biovar 1-Agrobacterium radiobacter (Sawada et al., 1993), Agrobacterium tumefaciens (Bouzar, 1994) or Rhizobium radiobacter (Young et al., 2001)-are not relevant in view of the genomic diversity of the biovar. De Ley et al. (1973), De Ley (1974) and Popoff et al. (1984) have already shown that agrobacteria belonging to biovar 1 group into at least nine genomic species that have not yet received accepted nomenspecies status. The nine genomic species that cluster in biovar 1 are separated by canonical values of relative DNA-DNA hybridization and $\Delta T_{\mathrm{m}}$. For this reason, biovar 1 as studied by Popoff et al. (1984) appeared to be a relevant model for the purpose of the present study because DNA-DNA hybridizations were performed with closely related bacteria belonging to the same biovar cluster along with the more distantly related species Agrobacterium rubi and A. rhizogenes.

In this work, experimental AFLP analyses were performed with agrobacteria in order to provide a dataset to be used to verify our AFLP predictions. AFLP predictions were made on the basis of constraining nucleotides. These constraining nucleotides are the basis of our mathematical method for determining genome base mispairing. This method was validated by comparing our prediction of current genome mispairing based on AFLP with that based on DNA-DNA hybridization (determined previously by Popoff et al., 1984). A method for estimating evolutionary genome divergence was also proposed and then used for genome-based phylogenetic studies. 
Table 1. Agrobacterium strains used in this study

Abbreviations: ATCC, American Type Culture Collection, Manassas, VA, USA; CIP, Collection de l'Institut Pasteur, Paris, France; CFBP, Collection Française de Bactéries Phytopathogènes, INRA, Angers, France; LMG, Bacteria Collection Laboratorium voor Microbiologie, Universiteit Gent, Gent, Belgium; SCRI, Scottish Crop Research Institute, Invergowrie, Dundee, UK. Genomic groups were determined by Popoff et al. (1984) or, for A. vitis, by Ophel \& Kerr (1990). Strain TT111, strain C58 and its derivatives were assigned to genomic groups on the basis of other DNA-DNA relatedness studies. $A$. tumefaciens, A. rhizogenes and A. vitis are designated according to Bouzar (1994), Sawada et al. (1993) and Ophel \& Kerr (1990), respectively.

\begin{tabular}{|c|c|c|c|}
\hline Strain & Received from/as: & Relevant properties & rrs accession no." \\
\hline \multicolumn{4}{|c|}{ Genomic group 1 (Agrobacterium sp.) } \\
\hline TT111 & CFBP 4716 & Crown gall, USA & X67223 \\
\hline S56 & LMG 321 & Crown gall, USA & AJ389895 \\
\hline S377 & LMG 326 & Plant & (AJ389895) \\
\hline S4 & LMG 318 & Plant & \\
\hline ATCC 4720 & LMG 182 & Black raspberry, USA & \\
\hline \multicolumn{4}{|c|}{ Genomic group 2 (Agrobacterium sp.) } \\
\hline CIP 497-74 & CFBP 2884 & Human blood, France (Kiredjian, 1979) & AJ389894 \\
\hline CIP 28-75 & M. Kiredjian, France & Human urine, France (Kiredjian, 1979) & (AJ389894) \\
\hline CIP $127-76$ & M. Kiredjian, France & Human urine, Switzerland (Kiredjian, 1979) & (AJ389894) \\
\hline CIP 43-76 & M. Kiredjian, France & Human urine, France (Kiredjian, 1979) & (AJ389894) \\
\hline \multicolumn{4}{|c|}{ Genomic group 3 (Agrobacterium sp.) } \\
\hline CIP $111-78$ & M. Kiredjian, France & $\begin{array}{l}\text { Human cephalo-rachidian liquid, France } \\
\text { (Kiredjian, 1979) }\end{array}$ & AJ389897 \\
\hline \multicolumn{4}{|c|}{ Genomic group 4 (Agrobacterium tumefaciens) } \\
\hline $\begin{array}{l}\text { A. tumefaciens } \\
\text { ATCC } 23308^{\mathrm{T}}\end{array}$ & ATCC & Apple seedling, IA, USA $\left(=\right.$ Braun $\mathrm{B}^{\mathrm{T}}$ ) & D12784 \\
\hline $\begin{array}{l}\text { A. radiobacter } \\
\text { ATCC } 19358^{\mathrm{T}}\end{array}$ & ATCC & Soil & $(\mathrm{AJ} 389897)$ \\
\hline \multicolumn{4}{|c|}{ Genomic group 6 (Agrobacterium sp.) } \\
\hline NCPPB 925 & LMG 225 & Dahlia sp., South Africa & (AJ012209) \\
\hline Zutra F/1 & LMG 296 & Dahlia sp., Israel & AJ389909 \\
\hline \multicolumn{4}{|c|}{ Genomic group 7 (Agrobacterium sp.) } \\
\hline RV3 & LMG 317 & No information available & AJ389903 \\
\hline Zutra 3/1 & LMG 198 & Malus sp., Israel & (AJ389903) \\
\hline NCPPB 1641 & LMG 228 & Flacourtia ramontchi, UK & (AJ389903) \\
\hline \multicolumn{4}{|c|}{ Genomic group 8 (Agrobacterium sp.) } \\
\hline $\mathrm{C} 58$ & CFBP 1903 & Cherry tree gall, NY, USA & AJ012209 \\
\hline $\mathrm{C} 58 \mathrm{C} 1$ & CFBP 1902 & C58 cured of Ti plasmid pTiC58 & \\
\hline C58pAt- & Y. Dessaux, France & C58 cured of cryptic plasmid pAtC58 & \\
\hline GMI 9023 & T. Huguet, France & $\begin{array}{l}\text { C58 cured of both pTiC58 and pAtC58 } \\
\text { (Rosenberg \& Huguet, 1984) }\end{array}$ & \\
\hline T37 & LMG 332 & Walnut gall, CA, USA & (AJ012209) \\
\hline TT9 & LMG 64 & No information available & \\
\hline Mushin 6 & LMG 201 & Hop gall, Australia & (AJ012209) \\
\hline \multicolumn{4}{|c|}{ Genomic group 9 (Agrobacterium sp.) } \\
\hline Hayward 0363 & LMG 27 & John Innes potting soil, Australia & $(\mathrm{AJ} 389894)$ \\
\hline Hayward 0362 & LMG 26 & John Innes potting soil, South Australia & (AJ389894) \\
\hline \multicolumn{4}{|c|}{ Undetermined genomic group (Agrobacterium larrymoorei) } \\
\hline AF3.44 & H. Bouzar, USA & Ficus benjamina, FL, USA (Bouzar et al., 1995a) & Z30542 \\
\hline $\mathrm{Fb} 33$ & A. Zoina, Italy & Ficus benjamina, Salerno, Italy & (Z30542) \\
\hline Fb72 & A. Zoina, Italy & Ficus benjamina, Salerno, Italy & (Z30542) \\
\hline \multicolumn{4}{|c|}{ Genomic group 11 (Agrobacterium rubi) } \\
\hline LMG $17935^{\mathrm{T}}$ & LMG & Rubus ursinus, USA $\left(=\mathrm{TR} 3^{\mathrm{T}}\right)$ & D12787 \\
\hline \multicolumn{4}{|c|}{ Agrobacterium vitis (another genomic group) } \\
\hline CFBP 2617 & CFBP & Vitis vinifera, France & AJ389911 \\
\hline CFBP 2678 & CFBP & Vitis vinifera, France & AJ389910 \\
\hline CFBP 2736 & CFBP & Vitis vinifera, Australia (= Kerr K305) & AJ389912 \\
\hline
\end{tabular}


Table 1 (cont.)

\begin{tabular}{|lccc|}
\hline \multicolumn{1}{|c|}{ Received from/as: } & Relevant properties & rrs accession no.* \\
\hline $\begin{array}{l}\text { Genomic group 10 } \\
\text { CFBP } 2408^{\mathrm{T}}\end{array}$ & CFrobacterium rhizogenes) & & D 12788 \\
$\begin{array}{c}\text { Other strains } \\
\text { SCRI 551 }\end{array}$ & M. Perombelon, UK & Unassigned strain isolated from Rubus sp. & \\
\hline
\end{tabular}

* Accession numbers for sequences determined in this study are in bold. Numbers in parentheses represent sequences found to be identical to the accession shown.

\section{METHODS}

Bacterial strains and media. Bacteria used in the present study are members of the genus Agrobacterium (Table 1). Most of them belong to the genomic species (= genomic groups) determined by Popoff et al. (1984). This set of strains included type strains of $A$. tumefaciens, $A$. radiobacter (both of which are in genomic group 4), A. rhizogenes (group 10) and $A$. rubi (group 11). Other agrobacteria used in the study were as follows: (i) strains that could be attributed to the former genomic groups according to other DNA-DNA relatedness studies (De Ley et al., 1973; De Ley, 1974); (ii) strains of $A$. vitis; and (iii) members of a novel species (isolated from fig trees) called Agrobacterium larrymoorei (Bouzar \& Jones, 2001). The model also included derivatives of the standard strain C58 cured either of the Ti plasmid pTiC58 (C58C1) or of the cryptic plasmid pAtC58 (C58pAt-) or cured of both plasmids (GMI 9023).

Bacteria were grown routinely at $28{ }^{\circ} \mathrm{C}$ on mannitol/ glutamate agar, as described by Bouzar et al. (1995b); LB broth (low salt; Gibco-BRL) was used to cultivate bacteria before DNA preparation.

Isolation and quantification of DNA. Total bacterial DNAs were extracted by using the Dneasy tissue kit (Qiagen) according to the manufacturer's instructions. DNAs were quantified by using MOLECULAR ANALYST software (Bio-Rad) according to the manufacturer's instructions.

Predictive AFLP. AFLP fragments were predicted as described by Arnold et al. (1999) by looking for DNA restriction sites and selective nucleotides, using a wordprocessor and spreadsheet. The non-redundant published sequences of strain C58 available in GenBank and used for the prediction represented approximately $120 \mathrm{~kb}(2 \cdot 4 \%)$ of the chromosomes (AF024659, AF033856/U38977/L24117, AF039940, AF044495, AF090987, AF111855, J03678, L07902/M36776, L18860, L38609, M24198, M38670, M58472, U32867, U59485/L63540, U91632, U95165, $\mathrm{X} 68263, \mathrm{X} 69388, \mathrm{X} 87113, \mathrm{X} 95676)$ and $120 \mathrm{~kb}(50 \%)$ of pTiC58 (J03320, AF034769, AF010180, AF057718, L22207, AJ237588/AF065243/AF126445) or the complete sequence of the related pTiSakura (AB016260). The fragment-size data were adjusted to allow for the addition of adaptors.

AFLP and data processing. The AFLP Microbial Fingerprinting kit of Applied Biosystems was used according to the recommendations of the manufacturer. AFLP analyses were performed using a selective primer containing two selective nucleotides at the $3^{\prime}$ end (-CA or $-\mathrm{CC}$ or $-\mathrm{CG}$ or $-\mathrm{CT}$ ) of the fluorescent EcoRI-primer core (GACTGCGTACCAAT TC) and the non-fluorescent, non-selective MseI primer (GATGAGTCCTGAGTAA). Primer sets and the resulting AFLPs are identified in this work as $E c o \mathrm{RI}+\mathrm{CA} / \mathrm{Mse} \mathrm{I}+0$, $E c o \mathrm{RI}+\mathrm{CC} / M s e \mathrm{I}+0, E c o \mathrm{RI}+\mathrm{CG} / M s e \mathrm{I}+0$ and $E c o \mathrm{RI}+$
$\mathrm{CT} / \mathrm{MseI}+0$, respectively. The selective amplification of the two fragments released from rrs containing an EcoRI site was obtained as follows: (i) with a selective EcoRI primer with CA at the $3^{\prime}$ end used together with a selective $M s e$ I primer with GTCA at the $3^{\prime}$ end $(E c o \mathrm{RI}+\mathrm{CA} / M s e \mathrm{I}+$ GTCA condition) for the fragment left of the EcoRI site; (ii) with a selective EcoRI primer containing CG at the $3^{\prime}$ end used together with a selective $M s e$ I primer with TGCG at the $3^{\prime}$ end (EcoRI + CG/MseI + TGCG condition) for the fragment right of the EcoRI site. DNA samples processed accordingly were loaded singly or in pools of three with different fluorescent dyes on a $6 \%$ sequencing gel (GelMix 6, containing 5.7\% acrylamide, 0.3\% bis-acrylamide and $7 \mathrm{M}$ urea; Gibco-BRL) with an ABI PRISM 373 sequencer (Perkin-Elmer). The GENESCAN ANALYSIS software of Perkin-Elmer was used to extract data from electrophoregrams. At least two independent AFLP replicates were performed in order to retain, finally, only those peaks detected in all replicates. Assignment of fragments to discrete categories was done by using an iterative method called Lis, as follows: at each iteration, the program (i) finds the largest fragment; (ii) creates a category corresponding to the truncated value of the fragment size and (iii) assigns the same value to all fragment sizes between the maximum size and the maximum size minus $1 \mathrm{bp}$. The program continues with the next maximum. The program LecPCR was developed to transform fragment-size matrices into tabular binary matrices. The program DistAFLP calculates similarities (Jaccard or Dice index), current genome mispairing and evolutionary genome divergence with or without bootstrap resamplings. The programs LecPCR and DistAFLP are available on the ADE-4 web server (http://pbil.univlyon1.fr/ADE-4/microb/). In addition, DistAFLP can provide output files in the ADE-4 binary format suitable for multivariate analysis methods (Thioulouse et al., 1997).

AFLP similarities between pairs of bacteria. Similarities of AFLP patterns were calculated in two ways. The pattern similarity used for the comparison of current genome traits was determined using the Jaccard index $\left(S_{\mathrm{J} x y}\right)$. The similarity to the common ancestor of two strains required for phylogenetic studies was determined by using the Dice index $\left(S_{\mathrm{D} x y}\right)$. The indexes are calculated as

$S_{\text {J } x y}=n_{x y} /\left(n_{x y}+\Delta_{x y}\right)$

$S_{\mathrm{D} x y}=n_{x y} /\left[n_{x y}+\left(\Delta_{x y} / 2\right)\right]$

(equation 1) (equation 2)

in which $n_{x y}$ is the number of fragments common to both strains $x$ and $y$, and $\Delta_{x y}$ is the number of fragments found only in $x$ or only in $y$.

Mathematical model for estimating genome divergence from AFLP data. Let us begin with the assumption that the occurrence of a common AFLP fragment in two strains requires the identity of $r$ nucleotide sites (i.e. constraining 
nucleotides) involved in both restriction and amplification (i.e. the sites recognized by endonucleases and selective nucleotides, respectively). As a consequence, we determined the proportion of common AFLP fragments, $\mathrm{pF}$, as

$\mathrm{pF}=(1-d)^{r}$

(equation 3)

where $d$ is the rate of base mispairing between two genomes (i.e. genome mispairing). Conversely, we calculated the proportion of nucleotide differences as

$d=1-(\mathrm{pF})^{1 / r}$

(equation 4)

A measure of the current genome mispairing is given by $d_{\mathrm{J} x y}$ after substitution of $S_{\mathrm{J} x y}$ for $\mathrm{pF}$ in equation 4 , because the likelihood for the current number of sites $n_{x y}$ and $\Delta_{x y}$ is maximized by using the Jaccard index (Felsenstein, 2002).

For optimal phylogenetic studies, $d_{\mathrm{D} x y}$ is calculated after substitution of $S_{\mathrm{D} x y}$ for $\mathrm{pF}$ in equation 4 , because the Dice index is suited for phylogenetic studies, since it assumes that all sites that are shared between two strains were present in a common ancestor halfway between them (Felsenstein, 2002). The evolutionary distance is then corrected to account for unobserved substitutions by using the standard JukesCantor model (Swofford et al., 1996), which assumes equal rates of substitution between all pairs of bases.

Thus, the evolutionary genome divergence, expressed as the number of nucleotide substitutions per site, was estimated as

$\hat{t}=-(3 / 4) \ln \left[1-(4 / 3) d_{\mathrm{D} x y}\right]$

(equation 5)

In equation 5 , the maximum expected number of nucleotide differences per site is $d_{\mathrm{D} x y}=0 \cdot 75$. If $d_{\mathrm{D} x y}$ equals or exceeds this value, the distance becomes undefined. However, this is unlikely to occur with standard AFLP because $d_{\mathrm{D} x y}=0.75$ corresponds to $\mathrm{pF}<6 \times 10^{-8}$ for $r=12$, which is obtained only if $x$ and $y$ have no fragment in common at all.

Correction for fragment dependence. Bands seen on electrophoregrams that differ between strains $x$ and $y(\partial x y)$ are more numerous than AFLP fragments that really differ between strains $(\Delta x y)$ because, with some point mutations, bands move but do not disappear. For genomes that have diverged substantially, this may not be a problem - fragments that differ between species may tend to have their presence or absence fixed within each species. For withinspecies inferences, we determined a correction for fragment dependence, $K$, that is given by:

$\begin{aligned} \Delta_{x y}= & K \partial_{x y}=(1 / r)[\mathrm{E} /(1+\text { pEE.pE }) \\ & +\mathrm{M} /(1+\text { pMM.pM })+\mathrm{N}] \partial_{x y}\end{aligned}$

(equation 6)

in which $\mathrm{E}$ and $\mathrm{M}$ are the numbers of nucleotides in the $E c o$ RI and MseI sites, respectively, $\mathrm{N}$ is the number of selective nucleotides (note: $\mathrm{E}+\mathrm{M}+\mathrm{N}=r$ ), pEE and pMM are the proportions of fragments that produce two different bands in AFLP patterns following mutations in the EcoRI or $M s e$ I restriction site, respectively, and $\mathrm{pE}$ and $\mathrm{pM}$ are the respective probabilities of common EcoRI or MseI sites in both genomes. pEE and pMM were estimated from the proportion of fragments in agrobacterial sequences with identical EcoRI extremities and identical MseI extremities, respectively, that were short enough to be detected by the sequencing apparatus (i.e. below $500 \mathrm{bp}$ with ABI PRISM 373). Note that 'EcoRI and $M s e I$ extremities' means not only nucleotides involved in restriction sites but also the selective nucleotides added to the AFLP primers. $\mathrm{pE}=$ $(1-d)^{E}$ and $\mathrm{pM}=(1-d)^{M}$ are maximal for nearly identical strains and decrease with genome mispairing; thus, fragment dependence tends to be negligible between species. For simplicity, we use $\mathrm{pE}=\mathrm{pM}=1$ in the present version of DistAFLP.

Phylogenetic analyses. Phylogenetic analyses were performed with the phylogenetic inference package PHYLIP (Felsenstein, 1993). Bootstrapped dendrograms were constructed by using the neighbour-joining method (Felsenstein, 1985; Saitou \& Nei, 1987). In the case of bootstraps, distance data were not corrected for fragment dependence as explained above, but involved sampling $K \%$ of fragments at random among the $100 \%$, according to the proposal of Felsenstein (1985), to cope with fragment dependence. Parsimony and maximum-likelihood analyses were done by using the DOLLO and RESTML programs of PHYLIP, respectively.

rrs sequencing and analysis of the ribosomal intergenic spacer. Sequencing was performed by the company Genome Express with rrs amplicons obtained as described previously (Bouzar et al., 1995a). The region lying between $\mathrm{rrs}$ and $\mathrm{rrl}$ (16S and 23S rRNA genes) was amplified and analysed as described previously (Ponsonnet \& Nesme, 1994).

\section{RESULTS}

DNA-DNA relatedness study and inferred phylogeny of the model system

The present study was based mainly on the model system described by Popoff et al. (1984), consisting of nine closely related genomic species (groups 1-9) within the single biovar 1 cluster of Agrobacterium. A first inference of the phylogenetic structure of the model system was obtained with the two direct measurements of genome similarity or divergence [i.e. relative binding ratio (RBR) at $70^{\circ} \mathrm{C}$ and at $80^{\circ} \mathrm{C}$, and $\Delta T_{\mathrm{m}}$ at $\left.70^{\circ} \mathrm{C}\right]$ obtained by Popoff and co-workers. Only two clusters were obtained consistently by the three methods: one cluster containing strains RV3, Hayward 0363 and ATCC 23308 (respectively from groups 7,9 and 4) and one cluster with strains T37 and NCPPB 925 (respectively groups 8 and 6). All other groupings were not supported by the three methods (data not shown). This phylogeny remained limited to a single strain per genomic group, because only one strain per genomic group was used to prepare the radioactively labelled (tracer) DNA. As a result, the consistency of the phylogeny obtained was unknown.

The bacterial collection of Popoff was then partly reconstructed for eight groups with the help of $\mathbf{M}$. Kiredjian (Institut Pasteur, Paris, France) and $\mathbf{M}$. Gillis (LMG, Gent, Belgium). PCR-RFLP analysis of the ribosomal intergenic spacer lying between $r r s$ and $r r l$ (16S and 23S rRNA genes) was used to verify that all the strains had readily differentiable genotypes. This was verified in all instances except for ICPB TT9 and T37 (from genomic group 8), which could not be differentiated using five different endonucleases (data not shown). On the other hand, sequencing revealed one EcoRI site in the rrs of all strains belonging to the biovar 1 cluster or to $A$. rhizogenes, although there is no EcoRI site in the rrs of $A$. rubi, A. larrymoorei and A. vitis. Thus, two Eco RI-MseI fragments, of 82 and $194 \mathrm{bp}$, would be released from all agrobacteria be- 
longing to biovar 1 , but the $194 \mathrm{bp}$ fragment alone was expected to occur in $A$. rhizogenes. These rrs fragments were used later to verify the quality of experimental AFLP analysis.

\section{AFLP fingerprinting of Agrobacterium species}

Digestion of genomic DNAs of Agrobacterium species with $E c o$ RI and $M s e I$ and amplifications with various primer sets characterized by two selective nucleotides consistently led to even distributions of AFLP fragments between 35 and $500 \mathrm{bp}$. By retaining only those fragments detected in two independent replicates (independent AFLP analyses performed with independently extracted DNA), the mean numbers of AFLP fragments per strain ( \pm mean difference) were respectively $36 \cdot 4 \pm 4 \cdot 0,26 \cdot 6 \pm 3 \cdot 4,37 \cdot 1 \pm 5 \cdot 1$ and $39 \cdot 4 \pm$ 6.5 for $E c o \mathrm{RI}+\mathrm{CA} / \mathrm{Mse} \mathrm{I}+0, E c o \mathrm{RI}+\mathrm{CC} / \mathrm{Mse}+\overline{0}$, $E c o \mathrm{RI}+\mathrm{CG} / \mathrm{Mse} \mathrm{I}+0$ and $E c o \mathrm{RI}+\mathrm{CT} / M s e \mathrm{I}+0$ and $139 \cdot 4 \pm 14 \cdot 0$ with combined AFLP data.

All data used in this study are available through anonymous FTP (ftp://pbil.univ-lyon1.fr/pub/datasets/IJSEM2001/).

\section{Predictive AFLP}

To assess the accuracy of experimental AFLP analysis, the correspondence of predicted and experimental AFLPs was determined. Using all non-redundant chromosomal and Ti plasmid sequence data currently available in databases (representing about $5 \%$ of the whole genome of C58), 20 fragments were predicted by looking for restriction and selective nucleotide sites in sequences for $E c o \mathrm{RI}+\mathrm{CA} / \mathrm{Mse}+0, E c o \mathrm{RI}+\mathrm{CC} /$ $M s e \mathrm{I}+0, \quad E c o \mathrm{RI}+\mathrm{CG} / M s e \mathrm{I}+0$ and $E c o \mathrm{RI}+\mathrm{CT} /$ $M s e I+0$ conditions. With C58 DNA, experimental AFLPs revealed a total of 152 fragments, of which 17 had the expected sizes of the 20 predicted by the simulation, corresponding to $85 \%$ prediction accuracy (Table 2). The correspondence between the expected and the experimental fragments was verified experimentally for both rrs and Ti plasmid fragments.

\section{Detection of $r$ rs fragments}

As indicated above, an EcoRI site occurred in the rrs of most but not all agrobacteria. This gave us the opportunity to estimate the AFLP quality of individual strains by looking for the occurrence of rrs fragments in experimental AFLPs. The rrs sequencing showed that $E c o \mathrm{RI}+\mathrm{CA} / \mathrm{Mse} \mathrm{I}+\mathrm{GTCA}$ and $E c o \mathrm{RI}+\mathrm{CG} /$ $\mathrm{Mse}$ + TGCG conditions for AFLP analysis would allow amplification of two rrs restriction fragments in most strains of Agrobacterium. As predicted, a single fragment of approximately $109 \mathrm{bp}$ (i.e. $82 \mathrm{bp}$ from $\mathrm{rrs}$ plus 13 and $14 \mathrm{bp}$ for EcoRI and MseI adaptors, respectively) was obtained with $E c o \mathrm{RI}+\mathrm{CA} / \mathrm{Mse} \mathrm{I}+$ GTCA conditions for all strains belonging to the biovar 1 cluster, but not for A. rubi, A. larrymoorei or $A$. rhizogenes (data not shown). A $109 \mathrm{bp}$ fragment was also found among the numerous fragments obtained by using the less-selective EcoRI $+\mathrm{CA} / M s e \mathrm{I}+$ 0 conditions. As also predicted from $r r s$ sequences, the $E c o$ RI $+\mathrm{CG} / \mathrm{Mse}$ I TGCG condition allowed the amplification of a single fragment of approximately $223 \mathrm{bp}$ in all strains belonging to biovar 1 and in $A$. rhizogenes (data not shown). A fragment of the same size was also found among the numerous fragments obtained with the less-selective EcoRI $+\mathrm{CG} / M s e \mathrm{I}+0$ conditions in the same strains. However, a $223 \mathrm{bp}$ fragment was also found for A. larrymoorei strain AF3-44. This was not an rrs fragment, since there is no EcoRI site in the rrs of this species (Bouzar et al., 1995a). Thus, this fragment is assumed to be one that co-migrated with the rrs fragment but which originated from an other genome region (i.e. homoplasy).

\section{AFLP fragments originating from pTiC58}

Comparisons of AFLPs performed with Ti plasmidcontaining and plasmid-free strains were used to verify experimentally the correspondence between expected and observed fragments. Eleven fragments found in experimental AFLPs with C58 or C58pAt - were lacking from AFLPs performed with Ti plasmid-free derivatives C58C1 and GMI 9023 (see data followed by asterisks in Table 2). Nine of these fragments were effectively expected to originate from the Ti plasmid by predictive AFLP analysis performed with available sequences of pTiC58 or the complete sequence of the related Ti plasmid pTiSakura. Two fragments identified by experimental AFLP analysis to be specific for pTiC58 were not predicted. On the other hand, two fragments predicted to originate from the Ti plasmid were detected not only in C58 but also in C58 derivatives cured of the Ti plasmid (AFLP fragments of 187.9 and $261.7 \mathrm{bp}$ with $E c o \mathrm{RI}+\mathrm{CA} / M s e \mathrm{I}+0$ conditions). This suggests that the Ti-plasmid fragments co-migrated with chromosomal fragments and that the chromosomal fragments still remained in AFLP analysis performed with Ti plasmid-free strains.

\section{AFLP fragments originating from pAtC58}

Experiments also showed the occurrence of AFLP fragments specific to pAtC58 (Table 2). However, no sequences of pAtC58 were available for AFLP predictions.

\section{Current genome mispairing and DNA-DNA reassociation values}

With combined AFLP data, and after assignment of fragments to discrete categories, the number of common fragments per pair of strains was found to vary from 8 to 130 (data not shown). Current genome mispairings were calculated by using $d_{\mathrm{J} x y}$ with $r=12$ and equations 1 and 4. With Agrobacterium, the $E c o$ RI/MseI conditions for AFLP analysis using two selective nucleotides added to the EcoRI primer required a correction factor $(K=0.89)$ that was 
Table 2. Comparison of predictive and experimental AFLP analyses performed with A. tumefaciens strain C58 and plasmid-free derivatives of C58 under four AFLP conditions

Sizes of fragments are indicated as Predicted (fragments theoretically released by double digestion with EcoRI and $M s e I$ ), Expected (tagged fragments theoretically amplified by AFLP under the conditions indicated) or Detected (mean sizes of fragments obtained in experimental AFLP analyses). Bold type indicates putative 16S rRNA gene fragments detected under the AFLP conditions indicated and confirmed as being true rrs fragments by using highly selective AFLP conditions $(E c o \mathrm{RI}+\mathrm{CA} / M s e \mathrm{I}+\mathrm{GTCA}$ and

EcoRI + CG/MseI + TGCG; see text).

\begin{tabular}{|c|c|c|c|}
\hline Fragment & Predicted & Expected & Detected \\
\hline \multicolumn{4}{|c|}{$E c o R I+C A / M s e I+0$} \\
\hline \multicolumn{4}{|c|}{ C58 chromosome } \\
\hline 1 & 82 & 109 & $109 \cdot 4$ \\
\hline 2 & 192 & 219 & $220 \cdot 7$ \\
\hline 3 & 270 & 297 & ND \\
\hline 4 & 429 & 456 & $455 \cdot 9$ \\
\hline \multicolumn{4}{|l|}{ pTiC58 } \\
\hline 1 & 10 & 37 & ND \\
\hline 2 & 80 & 107 & $107 \cdot 7 *$ \\
\hline 3 & 161 & 188 & $187 \cdot 9$ \\
\hline 4 & 234 & 261 & $261 \cdot 7$ \\
\hline \multicolumn{4}{|l|}{ pAtC58† } \\
\hline 1 & - & - & $72 \cdot 3$ \\
\hline 2 & - & - & $78 \cdot 7$ \\
\hline \multicolumn{4}{|c|}{$E c o R I+C C / M s e I+0$} \\
\hline \multicolumn{4}{|c|}{ C58 chromosome } \\
\hline No fragments & - & - & - \\
\hline \multicolumn{4}{|l|}{ pTiC58 } \\
\hline 1 & 47 & 74 & $74 \cdot 9 *$ \\
\hline 2 & 82 & 109 & $109 \cdot 3 *$ \\
\hline 3 & 302 & 329 & $329 \cdot 8^{*}$ \\
\hline 4 & 361 & 388 & $389 \cdot 9 *$ \\
\hline \multicolumn{4}{|l|}{ pAtC58† } \\
\hline 1 & - & - & $258 \cdot 4$ \\
\hline 2 & - & - & $300 \cdot 9$ \\
\hline 3 & - & - & $496 \cdot 8$ \\
\hline \multicolumn{4}{|c|}{$E c o R I+C G / M s e I+0$} \\
\hline \multicolumn{4}{|c|}{ C58 chromosome } \\
\hline 1 & 168 & 195 & $196 \cdot 2$ \\
\hline 2 & 194 & 221 & $222 \cdot 8$ \\
\hline 3 & 424 & 451 & $453 \cdot 5$ \\
\hline \multicolumn{4}{|l|}{ pTiC58 } \\
\hline 1 & 34 & 61 & $61 \cdot 8 *$ \\
\hline 2 & NP & NP & $111 \cdot 74 *$ \\
\hline \multicolumn{4}{|l|}{ pAtC58† } \\
\hline 1 & - & - & $147 \cdot 2$ \\
\hline 2 & - & - & $397 \cdot 1$ \\
\hline \multicolumn{4}{|c|}{$E c o \mathrm{RI}+\mathrm{CT} / \mathrm{Mse} \mathrm{I}+\mathbf{0}$} \\
\hline \multicolumn{4}{|c|}{ C58 chromosome } \\
\hline 1 & 430 & 457 & $458 \cdot 0$ \\
\hline \multicolumn{4}{|l|}{ pTiC58 } \\
\hline 1 & 79 & 106 & $107 \cdot 1^{*}$ \\
\hline 2 & 81 & 108 & $\mathrm{ND}$ \\
\hline
\end{tabular}

Table 2 (cont.)

\begin{tabular}{|cccc|}
\hline Fragment & Predicted & Expected & Detected \\
\hline 3 & $\mathrm{NP}$ & $\mathrm{NP}$ & $223 \cdot 3^{*}$ \\
4 & 261 & 288 & $289 \cdot 4^{*}$ \\
5 & $\mathrm{NP}$ & $\mathrm{NP}$ & $464 \cdot 6^{*}$ \\
$\mathrm{pAtC} 58^{\dagger} \dagger$ & & & \\
1 & - & - & $260 \cdot 7$ \\
2 & - & - & $303 \cdot 2$ \\
\hline
\end{tabular}

ND, Expected but not detected experimentally.

NP, Not predicted but found in C58 and absent from Ti plasmidcured derivatives.

* Fragment found experimentally to be specific to pTiC58 (i.e. present in $\mathrm{C} 58$ or C58pAt - but absent from C58C1 or GMI 9023, C58 derivatives cured of pTiC58).

$\uparrow$ No sequence was available for pAtC58 in order to perform predictive AFLP with this plasmid.

calculated from equation 6 after determination of pEE and pмм (0.014 and 0.439 , respectively) with sequences of chromosomes of C58 and with pTiSakura.

Current genome mispairing - or current genome base similarity deduced from the former measure - was compared to DNA-DNA reassociation values obtained previously by Popoff et al. (1984). The RBRs at 70 and $80{ }^{\circ} \mathrm{C}$ were found to be highly correlated to current genome base similarity $\left(r^{2}=0.81\right.$ and $0 \cdot 74$, respectively), while $\Delta T_{\mathrm{m}}$ was significantly correlated to current genome mispairing $\left(r^{2}=0 \cdot 52\right)$. High correlation scores and significant linear regressions were obtained by considering only pairs of bacteria belonging to the same genomic group (Fig. 1). Significant correlations were also obtained when the linear model included inter-specific distances obtained with strains belonging to the most closely related genomic species revealed previously by DNA-DNA hybridization studies (i.e. groups 6 and 8 for one cluster and groups 4, 7 and 9 in another cluster) (data not shown). However, there was no significant correlation among distances for more-distantly related strains belonging to more-different genomic species $\left(r^{2}=0.34,0.04\right.$ and 0.08, respectively; Fig. 1).

\section{Current genome mispairing between closely and distantly related strains}

The genome differences between $\mathrm{C} 58$ and its plasmidcured derivatives are shown in Table 3 . The maximum genome difference, $1 \cdot 2 \%$, was obtained between C58 and GMI 9023 (Table 3). For a comparison, the current genome mispairing was $1.9 \%$ between the most closely related strains of the present model - T37 and TT9, which could not be differentiated by PCRRFLP analysis of the $r r s-r r l$ intergene. This showed that large $\mathrm{Ti}$ and pAt plasmids had relatively little effect upon estimates of genome mispairing.

The highest current genome mispairing between members of the same species was 13\% (between RV3 and 

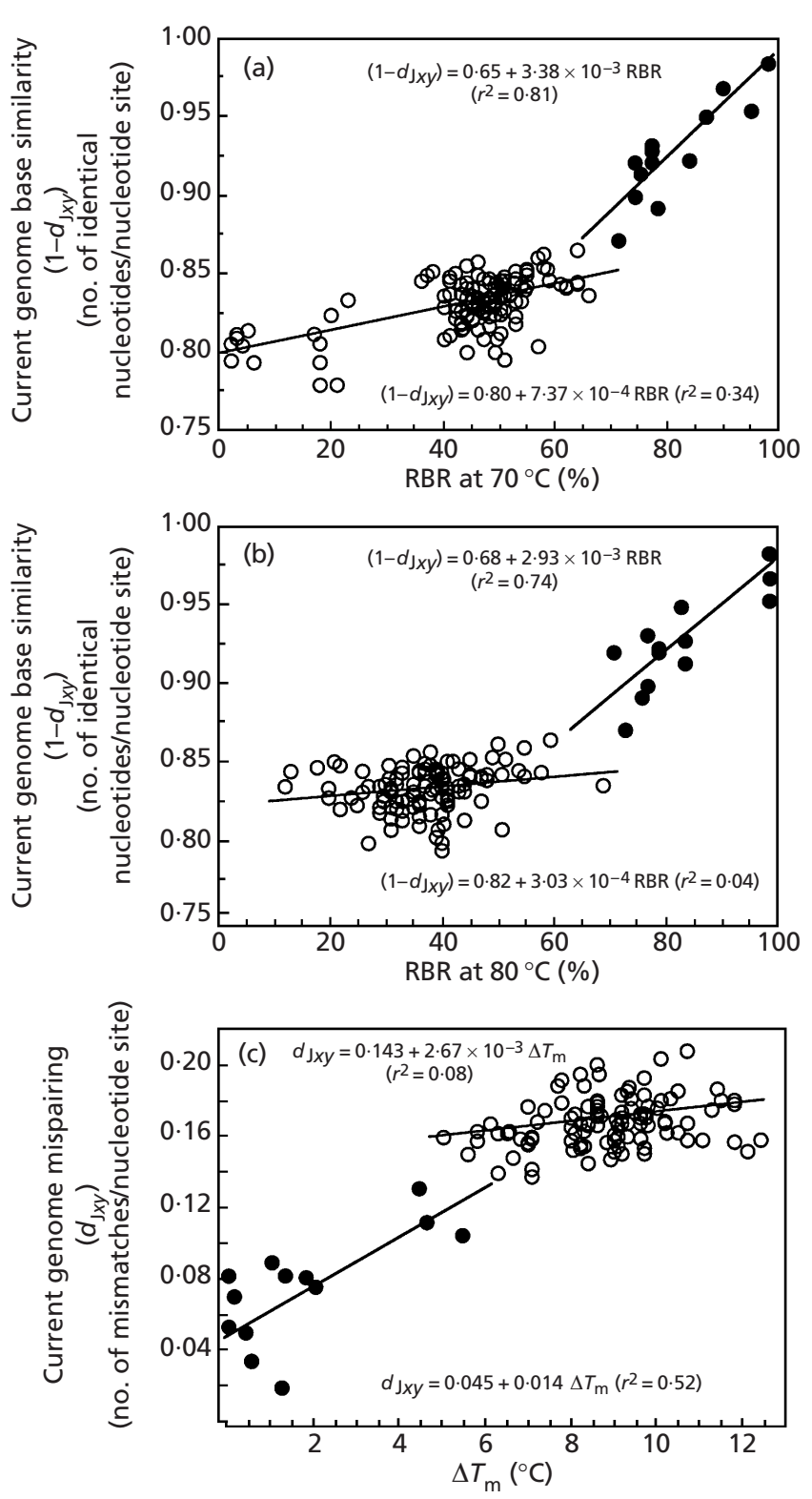

Fig. 1. Correlations between RBR at $70^{\circ} \mathrm{C}(\mathrm{a}), \mathrm{RBR}$ at $80^{\circ} \mathrm{C}$ (b) or $\Delta T_{\mathrm{m}}$ (c) and current genome base similarity (or mispairing) determined by AFLP analysis. Values obtained between bacteria belonging to the same genomic species of Agrobacterium (0) and between different genomic species $(\bigcirc)$ are shown.

Zutra 3/1 within group 7). The shortest divergence found between members of different species was $13.6 \%$ (between RV3 and Hayward 0363, respectively from groups 7 and 9).

\section{Phylogenetic analysis}

The evolutionary genome divergence, which is an estimate of the rate of nucleotide substitution since the divergence from the common ancestor, was given by $\hat{t}$, obtained from equations $2,4,5$ and 6 . Using this metric, the phylogenetic analysis showed in all cases
Table 3. Genome differences between C58 and C58 derivatives cured of pTiC58 and/or pAtC58

Values above the diagonal are percentages of similarity of AFLP patterns $\left(S_{J x y}\right)$ and (in parentheses) current genome mispairing $\left(d_{\mathrm{J} x y}\right)$. Values on the diagonal are combined numbers of fragments obtained between pairs of strains under $E c o \mathrm{RI}+\mathrm{CA} / M s e \mathrm{I}+0, E c o \mathrm{RI}+\mathrm{CC} / M s e \mathrm{I}+0$,

$E c o \mathrm{RI}+\mathrm{CG} / M s e \mathrm{I}+0$ and $E c o \mathrm{RI}+\mathrm{CT} / M s e \mathrm{I}+0 \mathrm{AFLP}$ conditions. Values below the diagonal are combined numbers of common AFLP fragments between pairs of strains.

\begin{tabular}{|lcccc|}
\hline Strain & C58 & C58C1 & C58pAt - & GMI 9023 \\
\hline C58 & 152 & $93 \cdot 5(0 \cdot 0056)$ & $94 \cdot 7(0 \cdot 0045)$ & $87 \cdot 1(0 \cdot 0115)$ \\
C58C1 & 141 & 141 & $88 \cdot 1(0 \cdot 0105)$ & $93 \cdot 1(0 \cdot 0060)$ \\
C58pAt - & 143 & 132 & 143 & $91 \cdot 9(0 \cdot 0070)$ \\
GMI 9023 & 132 & 132 & 132 & $134^{*}$ \\
\hline
\end{tabular}

* Two fragments not detected in C58, C58C1 or C58pAt - were obtained from GMI 9023.

that strains belonging to the same genomic species clustered significantly, as supported by high bootstrap values of dendrograms obtained with the neighbourjoining method (Fig. 2). This was verified for the targeted genomic species within biovar 1 and for other genomic species $A$. vitis and $A$. larrymoorei, but also for the type strain of $A$. rubi, which clustered significantly with another strain isolated from Rubus. Similar dendrograms were obtained with the maximum-likelihood method as well as with parsimony methods. The same significant branchings corresponding to genomic species were obtained with neighbour-joining and parsimony as well (data not shown). Other significant branchings were found at the infraspecific level, but no branching was significant at the interspecific level.

The highest evolutionary genome divergence $(\hat{t})$ found within a species was 0.097 nucleotide substitutions per site (for RV3 and Zutra 3/1) and the lowest between close, but different, species was $0 \cdot 104$ (for RV3 and Hayward 0363).

\section{DISCUSSION}

In this work, we propose a mathematical method, based on AFLP data, for determining genome divergence for microbial taxonomic and phylogenetic studies. For this purpose, we used the Agrobacterium strains studied by Popoff et al. (1984) as a model system, because the latter work provided data from DNA-DNA hybridizations performed with nine closely related genomic species belonging to the same biovar cluster. Moreover, the authors had used the nuclease S1 method considered most suited to that purpose by Grimont et al. (1980). In addition, complete tabular data for RBRs at $70^{\circ} \mathrm{C}$, at $80^{\circ} \mathrm{C}$ and for $\Delta T_{\mathrm{m}}$ were available; 70 and $80^{\circ} \mathrm{C}$ are the optimal and stringent reassociation temperatures, respectively, 


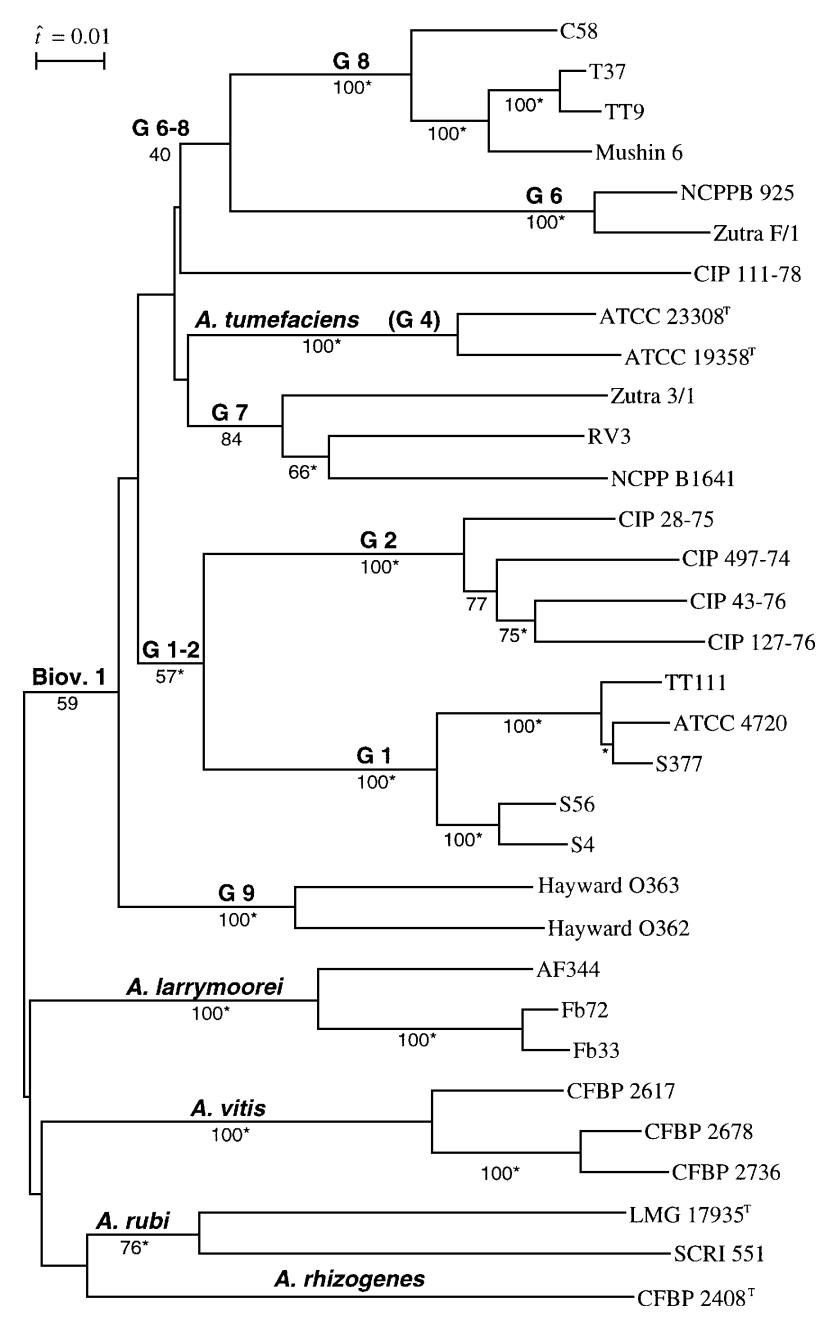

Fig. 2. Phylogenetic relationships amongst Agrobacterium strains inferred from evolutionary genome divergences determined by AFLP analysis. The dendrogram was obtained by using the neighbour-joining method with the estimated ratio of nucleotide substitution over whole genomes $(\hat{t})$. Branching robustness is expressed as the percentage reliability after 1000 bootstrap resamplings corrected for fragment dependence. Asterisks indicate branchings that were also supported by a bootstrapped parsimony method. The bar indicates the rate of base substitutions. G1-G9 are genomic species determined by Popoff et al. (1984) in biovar 1.

for bacteria with a $\mathrm{G}+\mathrm{C}$ content between 58 and $60 \mathrm{~mol} \%$ (Wetmur \& Davidson, 1968). RBRs between the genomic species clustered in biovar 1 of Agrobacterium were in the critical range (between 40 and 69\%) that required the $\Delta T_{\mathrm{m}}$ to be clearly delineated. Thus, the model was found to be highly relevant for testing whether the AFLP method, correlated with the nuclease $\mathrm{S} 1$ method, is able clearly to delineate genomic species that are so closely related.

Predictive AFLP analysis was used to test the quality of experimental AFLP data by using partial sequences of the standard strain, C58. In view of the fact that AFLP prediction was not done for the complete genome sequence, but only for $5 \%$ of it, the present prediction accuracy of $85 \%$ (Table 2) is in agreement with the $92 \%$ accuracy achieved for predictions done for the complete genome sequence of Escherichia coli K-12 MG1655 by Arnold et al. (1999). Moreover, by using plasmid-containing and plasmid-free derivatives of the same strain, or by using AFLP conditions designed for specific amplification of rrs fragments known to be present in most (but not all) agrobacteria, we found an excellent correlation between expected and experimentally determined fragments. However, the rare discrepancies are caused by some limitations of the method. Arnold et al. (1999) reported that adjacent fragments can sometimes be confused because of the inability to discriminate single-base-pair differences in the lower part of the gel and that unpredicted fragments occurred more frequently with primers having two selective nucleotides. Conversely, the absence of a predicted fragment could be caused by the sensitivity of endonucleases to DNA methylation. To our knowledge, methylation of EcoRI and MseI sites is not documented for Agrobacterium. However, DNA methylation is known to be a cell-cycle regulator in bacteria (Reisenauer et al., 1999), and a recent report indicates that methylation of GA(N)TC sites by CcrM is an essential function that is cell-cycle regulated in Agrobacterium (Kahng \& Shapiro, 2001). Thus, methylation could possibly affect experimental AFLPs and can cause pattern differences not related to real genome differences. This may explain the occurrence of two fragments in GMI 9023 that were not found in C58 (Table 2), i.e. if the absence of plasmids had modified the DNA methylation of the former. It could also explain why we never found environmental isolates of agrobacteria with completely identical AFLP patterns (our unpublished results). Alternatively, discrepancies could be caused by failures of the prediction itself, because it is known that sequencing errors are present in sequences deposited in databases. The success of predictive AFLPs indicates that AFLP data accurately reflect genome composition and that the method could be used to calculate genome mispairing.

In this work, mathematical formulae are proposed for calculating genome divergence for comparison with DNA-DNA hybridization values and for determining phylogenic relationships. The current degree of genome mispairing was determined by using the number of nucleotide sites constraining the technique. Our method is identical to that of Li \& Graur (1991) and gives results similar to the log formula of Upholt (1977); however, both of these were proposed for the analysis of restriction-site data rather than AFLP. Our proposition is in agreement with that of Felsenstein (2002), who indicated that, from a mathematical point of view and in spite of their detection as fragments, the statistical behaviour of AFLP bands is similar to that of restriction sites (i.e. unlike RFLP bands) and that restriction-site distance and parsimony methods can be used with AFLP data. A major feature of interest in 
the mathematical methods presently proposed is that they clearly show the importance of the constraining nucleotides in calculations of evolutionary genome divergence. Contrary to what has been done by most authors, including us in a previous study (Clerc et al., 1998), fingerprint similarity should not be used directly for phylogenetic purposes because the relationship between genome divergence and fingerprint similarity is not linear.

A correction of AFLP-pattern similarity was done to take into account the probability of a given fragment mutating into two detectable bands in electrophoregrams. To our knowledge, this is the first time that such a correction has been proposed, because AFLPs are generally assumed to give independent fragments that originate from different genome regions (Zabeau \& Vos, 1993; Felsenstein, 2002). This assumption is reasonable for AFLP analyses performed with large eukaryotic genomes that require a large number of constraining nucleotides ( $r=14$ or more). However, the shorter, prokaryotic genomes require fewer constraining nucleotides $(r=12$ in the present study). The estimation of the correction factor $(K)$ requires the availability of significantly long sequences of targeted genomes to predict the mean length of a restriction fragment. Sequence analysis showed that EcoRI sites and MseI sites are respectively 1.95- and $0 \cdot 45$-fold more frequent than expected from the $\mathrm{G}+\mathrm{C}$ content (data not shown) because of the characteristic genome 'signature' (sensu Karlin et al., 1998) of Agrobacterium. This resulted in the occurrence of a detectable number of EcoRI-EcoRI fragments containing no MseI site, leading us to add the selective nucleotides to the EcoRI primer to avoid the amplification of EcoRI-EcoRI fragments. Nevertheless, the prediction also showed that $K$ depends upon the number and the positions of the selective nucleotides determined by the characteristic genomic signature of the target bacteria, and adding selective nucleotides to both EcoRI and MseI primers would lead to a larger correction factor. In our opinion, this correction factor must be applied in order to achieve the most accurate estimate of genome divergence at the infraspecific level, but also for correcting bootstraps, as proposed by Felsenstein (1985). The determination of the correction factor will become more and more feasible with the increasing availability of complete genome sequences for numerous phyla.

The current genome mispairing calculated from AFLP data in the present work seems to agree with intrinsic genome parameters. The reduction in the thermal stability of reassociated hybrid DNA is directly proportional to the sequence difference (as a percentage base-pair mismatch) between reannealed single strands (Werman et al., 1996). The conversion between $\Delta T_{\mathrm{m}}$ values and the percentage mismatch compiled from the literature by Werman et al. (1996) varied from 0.7 to $2.0 \%$ base-pair mismatch per degree Celsius depression in $\Delta T_{\mathrm{m}}$, and the rate of divergence, calculated more rigorously by Springer et al. (1992), was $1 \cdot 18 \%$ sequence divergence per degree Celsius. In the present work, the regression calculated between $\Delta T_{\mathrm{m}}$ and $d_{\mathrm{J} x y}$ gave a slope of $1.4 \%$ mismatch per degree Celsius depression (between 0.5 and $2.2 \%$ at the $95 \%$ confidence level) (Fig. 1), which fits very well with the data reported by Werman et al. (1996). This shows that the proposed mathematical method gave a correct determination of the current genome mispairing.

A highly significant linear correlation was found between RBRs and current genome mispairing calculated from AFLP data. A linear correlation between sequence identities and hybridization values was, however, not expected, since the latter give only relative similarity values between genomes (RosselloMora \& Amann, 2001). Single-stranded DNA from two different strains will reassociate to a measurable extent and form a DNA hybrid if the strands contain more than $85 \%$ base similarity (Ullmann \& McCarthy, 1973). Thus, for a value of $50 \%$ DNA-DNA hybridization, half of the genomes have less than $85 \%$ base similarity and do not hybridize, while the half that hybridizes will have more than $85 \%$ base similarity, resulting in a median value of $85 \%$. In the present work, an extrapolated value of $82 \%$ current genome mispairing was obtained for $50 \%$ DNA-DNA hybridization with the linear regression (RBR at $70{ }^{\circ} \mathrm{C}$, Fig. $1)$, agreeing well with expectations and showing the accuracy of the current genome mispairing determination.

The relationship found between AFLP similarities and DNA-DNA hybridizations was not linear for all data (Fig. 1). This result, obtained in the present work for members of several genomic species of Agrobacterium, was similar to those obtained with several genomic species of Xanthomonas by Rademaker et al. (2000), who used a second-degree regression curve to fit the relationship. We found, however, that the correlation was linear when limited to related bacteria. We chose to perform separate statistics for infraspecific and interspecific distances because AFLP analysis has the unique property of clearly separating distributions of infraspecific and interspecific similarities. This was found in the present work with Agrobacterium, as well as with Pseudomonas tomato versus Pseudomonas syringae (Clerc et al., 1998), and was evidenced by the scatter plots presented by Rademaker et al. (2000) for Xanthomonas species. This clear-cut result is given by AFLP - or by related methods involving both restriction and selective amplification, such as the simplified AFLP method for Prokarya (Clerc et al., 1998) and presumably the infrequent restriction site/PCR method (Mazurek et al., 1996) - but not by randomly amplified polymorphic DNA analysis, BOX or other rep-PCR techniques (Clerc et al., 1998; Rademaker et al., 2000). This shows that AFLP analysis and related methods are particularly suited to the delineation of genomic species. As the relationship between AFLP similarities and DNA-DNA hybridizations is not the same for related and non-related strains, it is likely that estimates of genome similarity based on AFLP analysis 
(and, in turn, current genome mispairing and evolutionary genome divergence) are correct at the infraspecific level but not the interspecific level. The reason for the overestimation of interspecific similarities is likely to be related to homoplasy. AFLP fragments of the same size were assumed to originate from the same genome region, but the chance that they have originated from different genome regions increases with distantly related bacteria. As a consequence, AFLP fragments were falsely considered to be identical, and the genome divergences were underestimated in the case of interspecific comparisons. This could explain the lack of significance of the deepest branchings in phylogenetic studies.

The proposed method for determining genome divergence assumes that most differences between AFLP patterns are caused by point mutations. However, differences can also be caused by indels (i.e. insertions and deletions) or the presence of large plasmids. The effect of the latter source of variation was tested experimentally. Results indicated a small effect of plasmids upon the estimated genome mispairing. The entire C58 genome is $5750 \mathrm{~kb}$ in size, containing two chromosomes of 3000 and $2100 \mathrm{~kb}$ plus $450 \mathrm{~kb}$ for pAtC58 and $200 \mathrm{~kb}$ for pTiC58 (Allardet-Servent et al., 1993). The two large plasmids represent $13 \cdot 3 \%$ of the entire C58 genome. The dissimilarity of AFLP patterns between C58 and its plasmid-free derivative, GMI 9023, was $12.9 \%$ (Table 3), which is in good agreement with the expected value. This dissimilarity led to a genome mispairing equivalent to $1 \cdot 1 \%$. This value is smaller than the smallest genome mispairing value found between pairs of different strains in the present study. This very small genome divergence, $1.8 \%$ genome mispairing, occurred between strains T37 and TT9. These two strains could not be distinguished by RFLP-PCR analysis of the $16 \mathrm{~S}-23 \mathrm{~S}$ intergene, a method that is suited to the distinction of closely related agrobacteria (Ponsonnet \& Nesme, 1994). Thus, almost identical agrobacteria, included, until now, in the same 'strain' (sensu Tenover et al., 1995 ; i.e. isolates undistinguishable by methods such as ribotyping), showed higher current genome mispairing than strains having (or not having) two large plasmids. This is also true for larger plasmids or indels, since a calculation with equation 3 showed that, for $d_{\mathrm{J} x y}=13.6 \%$ current genome mispairing (which is the threshold between genomic species determined in the present study), the proportion of AFLP fragments differing between strains belonging to the same genomic species could be as high as $83 \%$ (for $\mathrm{pF}$ with $r=$ 12 constraining nucleotides). Thus, large horizontally transferred indels, such as the $32 \%$ sequence difference recorded between the genomes of Escherichia coli strains O157:H7 and K-12 MG1655 (Hayashi et al., 2001), would be equivalent to only $3 \%$ current genome mispairing and would therefore have only a limited effect upon strain assignation to the same genomic species.

For phylogenetic analysis, we used the evolutionary genome divergence instead of the current genome mispairing to take into account multiple base substitutions that had occurred since divergence. In agreement with the clear differences found previously between infraspecific and interspecific distances, genomic species were clearly delineated by phylogenetic analysis. Clusters corresponding to genomic species were supported in all instances by bootstrap resampling (Fig. 2), and strains that do not belong to the model of Popoff et al. (1984), such as C58, TT11 or SCRI 551, appeared in the expected clusters. Moreover, a significant clustering was also obtained with members of $A$. larrymoorei, which was expected to be a genomic species on the basis of rrs studies (Oger et al., 1998). Even though experimental DNA-DNA reassociation studies are still required to fulfil the recommendations of Wayne et al. (1987), the proposal that A larrymoorei is a genomic species is supported by the AFLP results given in the present work. The recent description of $A$. larrymoorei by Bouzar \& Jones (2001) confirms our evaluation and validates the ability of the AFLP method to delineate new genomic species.

Species assignment based on AFLP data requires a measure of the genome divergence that must be in agreement with former taxonomic recommendations. Wayne et al. (1987) indicate that species include strains with approximately $\geqslant 70 \%$ DNA-DNA relatedness and with a $\Delta T_{\mathrm{m}} \leqslant 5{ }^{\circ} \mathrm{C}$. The present study establishes that genomic species of Agrobacterium would include strains with approximately $\leqslant 13.6 \%$ whole-genome mispairing. A slightly higher value was calculated for Streptococcus aureus (our unpublished results), showing that the maximum genome mispairing of genomic species must be determined in several other taxa in order to determine a cut-off point equivalent to the $70 \%$ RBR. Conversely, the mispairing level found between Agrobacterium species determined in the present study is probably underestimated, but agrees with the mean sequence divergences found between closely related, but different, species reported in the literature for other taxa, such as that found between E. coli and Salmonella typhimurium (16\% sequence mismatch; Matic et al., 1995).

Both current genome mispairing and evolutionary genome divergence are interesting in the context of bacterial taxonomy. Work based upon partial sequencing has shown that sequence mispairing is directly responsible for the sexual isolation that leads to speciation in various taxa (Shen \& Huang, 1986; Vulic et al., 1997; Majewski \& Cohan, 1998; Majewski et al., 2000). Whole-genome mispairing estimated, for example, by AFLP (as described in this work) appears to be an intrinsic parameter specifically suited to bacterial phylogeny or population genetics, since it indicates directly how bacteria are potentially isolated sexually. For this reason, current genome mispairing could be used in future as an alternative to RBRs or $\Delta T_{\mathrm{m}}$ to describe genomic species. On the other hand, the evolutionary genomic distance is more suited to phylogenetic purposes. Interestingly, the threshold 
values of evolutionary distance obtained within and between genomic species (respectively 0.097 and 0.104 nucleotide substitutions) were determined objectively from the robust tree topology obtained after bootstrap resamplings of AFLP data.

Bootstrap resampling appears to be a method of paramount importance for the utilization of AFLP in taxonomy, since it supports clear and objective delineations of genomic species. The bootstrap method assumes that characters evolve independently (Felsenstein, 1985), and this assumption is generally recognized in AFLP data (Felsenstein, 2001). We found a small degree of fragment dependence between closely related bacteria (less than $11 \%$ ), which is assumed to be negligible between species. The bootstrap method can be used to delineate genomic species with AFLP data because a correction factor is used to cope with fragment dependence, as proposed by Felsenstein (1985). It is remarkable that the modified bootstrap method supports the inclusion of strain RV3 in genomic group 7 together with Zutra 3/1 (Fig. 2) in spite of the $13 \%$ genome mispairing found between the two strains, since this value is large and very close to the $13.6 \%$ genome mispairing with Hayward 0363 from genomic group 9. Very interestingly, the RBR values between RV3 and Zutra 3/1 and between RV3 and Hayward 0363 were respectively 72 and $68 \%$, and Popoff et al. (1984) needed to use $\Delta T_{\mathrm{m}}$ (respectively $4 \cdot 5$ and $8.2{ }^{\circ} \mathrm{C}$ ) to delineate genomic groups 7 and 9 clearly. Thus, it is likely that the bootstrap method could be used as an alternative to $\Delta T_{\mathrm{m}}$ to delineate very closely related genomic groups, providing the species contain several strains to form a cluster.

Since the proposal of Zuckerkandl \& Pauling (1965), macromolecules have been used increasingly for phylogeny. Genomes are probably the ultimate macromolecule for use for this purpose, and AFLP analysis could be used along with complete genome sequence analysis to estimate genome divergence. Whole genomes probably diverge more rapidly than is reported for genes, in agreement with the neutral mutation model of Kimura (1983), which is the basic hypothesis behind the concept of a molecular 'clock'. The calibration of the molecular clock proposed by Ochman \& Wilson (1987) indicated a sequence divergence of $0.02 \%$ per million years (My) for $r r s$ and $0 \cdot 7-0.8 \% \mathrm{My}^{-1}$ for genes encoding proteins. Taking the latter conversion as a maximum, if the shortest evolutionary genome divergence between species is $10.4 \%$ nucleotide substitution, this suggests that the agrobacterial genomic species probably diverged 13 My ago at the earliest. At the strain level, agrobacteria that are not differentiated by means of ribosomal intergenic spacers (like T37 and ICPB TT9 in the present study) show an evolutionary genome divergence of $1 \%$, resulting, perhaps, in a divergence that occurred 1.3 My ago. Dating of divergence, however, needs both a better calibration of the molecular clock for whole-genome divergence and an accurate estimate of genome divergence through AFLP.
The AFLP method as described in this study is a very useful and powerful tool for exploring bacterial genomes. The further delineation of bacterial species by a genomic approach could be based, in future, upon genome descriptions of individual strains obtained by AFLP analysis or equivalent methods and clustering supported by bootstrap resampling, in order eventually to replace DNA-DNA reassociation studies. In addition, this method could provide interesting estimates of genomic substitution rates suitable for reconstructing the evolutionary history of prokaryotes.

\section{ACKNOWLEDGEMENTS}

The authors wish to thank M. A. Poirier and K. Groud for skillful technical assistance, M. Gouy and J. Felsenstein for scientific counsel and T. Vogel for discussion and manuscript revision. The research was made possible with the kind help of M. Kiredjian and M. Gillis, who sent agrobacteria from the collection studied by Popoff. C. M. is a Research Fellow of the Institut National de la Recherche Agronomique. This work was part of INCO-DC European project ERB1C18CT970198 ('Integrated control of crown gall in Mediterranean countries') and was performed using the sequencing facilities of the DTAMB at Université Claude Bernard-Lyon 1.

\section{REFERENCES}

Allardet-Servent, A., Michaux-Charachon, S., Jumas-Bilak, E., Karayan, L. \& Ramuz, M. (1993). Presence of one linear and one circular chromosomes in the Agrobacterium tumefaciens C58 genome. $J$ Bacteriol 175, 7869-7874.

Arnold, C., Metherell, L., Clewley, J.P. \& Stanley, J. (1999). Predictive modelling of fluorescent AFLP: a new approach to the molecular epidemiology of E. coli. Res Microbiol 150, 33-44.

Bouzar, H. (1994). Request for a judicial opinion concerning the type species of Agrobacterium. Int J Syst Bacteriol 44, 373-374.

Bouzar, H. \& Jones, J. B. (2001). Agrobacterium larrymoorei sp. nov., a pathogen isolated from aerial tumours of Ficus benjamina. Int J Syst Evol Microbiol 51, 1023-1026.

Bouzar, H., Chilton, W. S., Nesme, X., Dessaux, Y., Vaudequin, V., Petit, A., Jones, J. B. \& Hodge, N. C. (1995a). A new Agrobacterium strain isolated from aerial tumours on Ficus benjamina L. Appl Environ Microbiol 61, 65-73.

Bouzar, H., Jones, J. B. \& Bishop, A. L. (1995b). Simple cultural tests for identification of Agrobacterium biovars. Methods Mol Biol 44, 9-13.

Caetano-Anollés, G., Bassam, B. J. \& Gresshoff, P. M. (1991). DNA amplification fingerprinting using very short arbitrary oligonucleotide primers. Biotechnology 9, 553-557.

Clerc, A., Manceau, C. \& Nesme, X. (1998). Comparison of randomly amplified polymorphic DNA with amplified fragment length polymorphism to assess genetic diversity and genetic relatedness within genospecies III of Pseudomonas syringae. Appl Environ Microbiol 64, 1180-1187.

Cohan, F. M. (1994). Genetic exchange and evolutionary divergence in prokaryotes. Trends Ecol Evol 9, 175-180.

De Ley, J. (1974). Phylogeny of procaryotes. Taxon 23, 291-300.

De Ley, J., Tijtgat, R., De Smedt, J. \& Michiels, M. (1973). Thermal stability of DNA:DNA hybrids within the genus Agrobacterium. J Gen Microbiol 78, 241-252.

Felsenstein, J. (1985). Confidence limits on phylogenies: an approach using the bootstrap. Evolution 39, 783-791. 
Felsenstein, J. (1993). PHYLIP: Phylogenetic Inference Package, version 3.5c. Seattle: University of Washington.

Felsenstein, J. (2002). Inferring Phylogenies. Sunderland, MA: Sinauer.

Fox, G. E., Wisotzkey, J. D. \& Jurtshuk, P., Jr (1992). How close is close: 16 rRNA sequence identity may not be sufficient to guarantee species identity. Int J Syst Bacteriol 42, 166-170.

Grimont, P. A. D., Popoff, M. Y., Grimont, F., Coynault, C. \& Lemelin, L. (1980). Reproducibility and correlation study of three deoxyribonucleic acid hybridization procedures. Curr Microbiol 4, 325-330.

Hauben, L., Vauterin, L., Moore, E. R. B., Hoste, B. \& Swings, J. (1999). Genomic diversity of the genus Stenotrophomonas. Int J Syst Bacteriol 49, 1749-1760.

Hayashi, T., Makino, K., Ohnishi, M. \& 19 other authors (2001). Complete genome sequence of enterohemorrhagic Escherichia coli O157:H7 and genomic comparison with a laboratory strain K-12. DNA Res 8, 11-22.

Janssen, P., Coopman, R., Huys, G., Swings, J., Bleeker, M., Vos, P., Zabeau, M. \& Kersters, K. (1996). Evaluation of the DNA fingerprinting method AFLP as a new tool in bacterial taxonomy. Microbiology 142, 1881-1893.

Kahng, L. S. \& Shapiro, L. (2001). The CcrM DNA methyltransferase of Agrobacterium tumefaciens is essential, and its activity is cell cycle regulated. J Bacteriol 183, 3065-3075.

Karlin, S., Campbell, A. M. \& Mrazek, J. (1998). Comparative DNA analysis across diverse genomes. Annu Rev Genet 32, 185-225.

Keane, P. J., Kerr, A. \& New, P. B. (1970). Crown gall of stone fruit. II: Identification and nomenclature of Agrobacterium isolates. Aust $J$ Biol Sci 23, 585-595.

Kersters, K., De Ley, J., Sneath, P. H. A. \& Sackin, M. (1973). Numerical taxonomic analysis of Agrobacterium. J Gen Microbiol 78, 227-239.

Kimura, M. (1983). The Neutral Theory of Molecular Evolution. Cambridge: Cambridge University Press.

Kiredjian, M. (1979). Le genre Agrobacterium peut-il être pathogène pour l'homme? Med Malad Infect 9, 223-235.

Li, W. H. \& Graur, D. (1991). Fundamentals of Molecular Evolution. Sunderland, MA: Sinauer.

Maidak, B. L., Cole, J. R., Lilburn, T. G. \& 7 other authors (2001). The RDP-II (Ribosomal Database Project). Nucleic Acids Res 29, 173-174.

Majewski, J. \& Cohan, F. M. (1998). The effect of mismatch repair and heteroduplex formation on sexual isolation in Bacillus. Genetics 148, 13-18.

Majewski, J., Zawadzki, P., Pickerill, P., Cohan, F. M. \& Dowson, C. G. (2000). Barriers to genetic exchange between bacterial species: Streptococcus pneumoniae transformation. J Bacteriol 182, 1016-1023.

Matic, I., Rayssiguier, C. \& Radman, M. (1995). Interspecies gene exchange in bacteria: the role of SOS and mismatch repair systems in evolution of species. Cell 80, 507-515.

Mazurek, G. H., Reddy, V., Marston, B. J., Haas, W. H. \& Crawford, J. T. (1996). DNA fingerprinting by infrequent-restriction-site amplification. J Clin Microbiol 34, 2386-2390.

Ochman, H. \& Wilson, A. C. (1987). Evolution in bacteria: evidence for a universal substitution rate in cellular genomes. $J$ Mol Evol 26, 74-86.

Oger, P., Dessaux, Y., Petit, A., Gardan, L., Manceau, C., Chomel, C. \& Nesme, X. (1998). Validity, sensitivity and resolution limit of the PCR-RFLP analysis of the rrs (16S rRNA gene) as a tool to identify soil-borne and plant-associated bacterial populations. Genet Sel Evol 30, S311-S321.

Ophel, K. \& Kerr, A. (1990). Agrobacterium vitis sp. nov. for strains of Agrobacterium biovar 3 from grapevines. Int J Syst Bacteriol 40, 236-241.
Panagopoulos, C., Psallidas, P. G. \& Alivizatos, A. S. (1978). Studies on biotype 3 of Agrobacterium radiobacter var. tumefaciens. In Proceedings of the IVth International Conference on Plant Pathogenic Bacteria, vol. I, pp. 221-228. Angers: Station de Pathologie Végétale et Phytobactériologie, INRA.

Perrière, G., Duret, L. \& Gouy, M. (2000). HOBACGEN: database system for comparative genomics in bacteria. Genome Res 10, 379-385.

Ponsonnet, C. \& Nesme, X. (1994). Identification of Agrobacterium strains by PCR-RFLP analysis of pTi and chromosomal regions. Arch Microbiol 161, 300-309.

Popoff, M. Y., Kersters, K., Kiredjian, M., Miras, I. \& Coynault, C. (1984). Position taxonomique de souches de Agrobacterium d'origine hospitalière. Ann Microbiol 135, 427-442.

Rademaker, J. L. W., Hoste, B., Louws, F. J., Kersters, K., Swings, J., Vauterin, L., Vauterin, P. \& de Bruijn, F. J. (2000). Comparison of AFLP and rep-PCR genomic fingerprinting with DNA-DNA homology studies: Xanthomonas as a model system. Int J Syst Evol Microbiol 50, 665-677.

Reisenauer, A., Kahng, L. S., McCollum, S. \& Shapiro, L. (1999). Bacterial DNA methylation: a cell cycle regulator? J Bacteriol 181, 5135-5139.

Rosenberg, C. \& Huguet, T. (1984). The pAtC58 plasmid of Agrobacterium tumefaciens is not essential for tumour induction. $\mathrm{Mol}$ Gen Genet 150, 53-61.

Rossello-Mora, R. \& Amann, R. (2001). The species concept for prokaryotes. FEMS Microbiol Rev 25, 39-67.

Saitou, N. \& Nei, M. (1987). The neighbor-joining method: a new method for reconstructing phylogenetic trees. Mol Biol Evol 4, 406-425.

Sawada, H., leki, H., Oyaizu, H. \& Matsumoto, S. (1993). Proposal for rejection of Agrobacterium tumefaciens and revised descriptions for the genus Agrobacterium and for Agrobacterium radiobacter and Agrobacterium rhizogenes. Int J Syst Bacteriol 43, 694-702.

Shen, P. \& Huang, H. V. (1986). Homologous recombination in Escherichia coli: dependence on substrate length and homology. Genetics 112, 441-457.

Spratt, B. G. (1999). Multilocus sequence typing: molecular typing of bacterial pathogens in an era of rapid DNA sequencing and the internet. Curr Opin Microbiol 2, 312-316.

Springer, M. S., Davidson, E. H. \& Britten, R. J. (1992). Calculation of sequence divergence from the thermal stability of DNA heteroduplexes. J Mol Evol 34, 379-382.

Stackebrandt, E. \& Goebel, B. M. (1994). Taxonomic note: a place for DNA-DNA reassociation and 16S rRNA sequence analysis in the present species definition in bacteriology. Int $J$ Syst Bacteriol 44, 846-849.

Swofford, D. L., Olsen, G. J., Waddell, P. J. \& Hillis, D. M. (1996). Phylogenic inference. In Molecular Systematics, 2nd edn, pp. 407-514. Edited by D. M. Hillis, C. Moritz \& B. K. Mable. Sunderland, MA: Sinauer.

Tenover, F. C., Arbeit, R. D., Goering, R. V., Mickelsen, P. A., Murray, B. E., Persing, D. H. \& Swaminathan, B. (1995). Interpreting chromosomal DNA restriction patterns produced by pulsed-field gel electrophoresis: criteria for bacterial strain typing. J Clin Microbiol 33, 2233-2239.

Thioulouse, J., Chessel, D., Dolédec, S. \& Olivier, J. M. (1997). ADE-4: a multivariate analysis and graphical display software. Stat Comput 7, 75-83.

Ullmann, J. S. \& McCarthy, B. J. (1973). The relationship between mismatched base pairs and the thermal stability of DNA duplexes. Biochim Biophys Acta 249, 416-424.

Upholt, W. B. (1977). Estimation of DNA sequence divergence from comparison of restriction endonuclease digests. Nucleic Acids Res 4, 1257-1265.

Versalovic, J., Koeuth, T. \& Lupski, J. R. (1991). Distribution of repetitive DNA sequences in eubacteria and application to fingerprinting of bacterial genomes. Nucleic Acids Res 19, 6823-6831. 
Vulic, M., Dionisio, F., Taddei, F. \& Radman, M. (1997). Molecular keys to speciation: DNA polymorphism and the control of genetic exchange in enterobacteria. Proc Natl Acad Sci U S A 94, 9763-9767.

Wang, Y. \& Zhang, Z. (2000). Comparative sequence analyses reveal frequent occurrence of short segments containing an abnormally high number of non-random base variations in bacterial rRNA genes. Microbiology 146, 2845-2854.

Wayne, L. G., Brenner, D. J., Colwell, R. R. \& 9 other authors (1987). International Committee on Systematic Bacteriology. Report of the ad hoc committee on reconciliation of approaches to bacterial systematics. Int J Syst Bacteriol 37, 463-464.

Werman, S. D., Springer, M. S. \& Britten, R. J. (1996). Nucleic acids I: DNA-DNA hybridization. In Molecular Systematics, 2nd edn, pp. 169-201. Edited by D. M. Hillis, C. Moritz \& B. K. Mable. Sunderland, MA: Sinauer.

Wetmur, J. G. \& Davidson, N. (1968). Kinetics of renaturation of DNA. J Mol Biol 31, 349-370.

Yanagi, M. \& Yamasato, K. (1993). Phylogenetic analysis of the family Rhizobiaceae and related bacteria by sequencing of 16S rRNA gene using PCR and DNA sequencer. FEMS Microbiol Lett 107, 115-120.

Yap, W. H., Zhang, Z. \& Wang, Y. (1999). Distinct types of rRNA operons exist in the genome of the actinomycete Thermomonospora chromogena and evidence for horizontal transfer of an entire rRNA operon. J Bacteriol 181, 5201-5209.

Young, J. M., Kuykendall, L. D., Martínez-Romero, E., Kerr, A. \& Sawada, H. (2001). A revision of Rhizobium Frank 1889, with an emended description of the genus, and the inclusion of all species of Agrobacterium Conn 1942 and Allorhizobium undicola de Lajudie et al. 1998 as new combinations: Rhizobium radiobacter, $R$. rhizogenes, $R$. rubi, R. undicola and R. vitis. Int J Syst Evol Microbiol 51, 89-103.

Zabeau, M. \& Vos, P. (1993). Selective Restriction Fragment Amplification: a General Method for DNA Fingerprinting. Publication 0534858 A1. Munich: European Patent Office.

Zuckerkandl, E. \& Pauling, L. (1965). Molecules as documents of evolutionary history. J Theor Biol 8, 357-366. 